\title{
Những rào cản trong chính sách bảo hộ quyền tác giả đối với truy cập mở và tài nguyên giáo dục mở
}

\author{
Trần Văn Hải* \\ Truòng Đại học Khoa học Xã hội và Nhân văn, Đại học Quốc gia Hà Nội, \\ 336 Nguyền Trãi, Thanh Xuân, Hà Nội, Việt Nam \\ Nhận ngày 07 tháng 8 năm 2017 \\ Chỉnh sửa ngày 22 tháng 9 năm 2017; Chấp nhận đăng ngày 10 tháng 10 năm 2017
}

\begin{abstract}
Tóm tắt: Sự ra đời của internet đã tác động không nhỏ đến lĩnh vực quyền tác giả, internet có thể giúp tác giả đưa tác phẩm của mình tới công chúng một cách thuận tiện, nhanh chóng. Nhưng internet cũng cho phép các hành vi sao chép trái phép tác phẩm, gây phương hại đến quyền tài sản của chủ sở hữu tác phẩm.

Trong lĩnh vực nghiên cứu khoa học, việc nhanh chóng chia sẻ kết quả nghiên cứu là cần thiết, nó giúp ích cho sự phát triển của khoa học và công nghệ, từ đó hình thành nhu cầu "truy cập mở" (Open Access). Trong lĩnh vực giáo dục và đào tạo, việc nhanh chóng đưa tri thức khoa học và công nghệ vào trường học là việc làm cấp bách, từ đó hình thành nhu cầu về "tài nguyên giáo dục mở" (Open Educational Resources). Truy cập mở và tài nguyên giáo dục mở không thể tách rời công cụ truy cập là internet, nhưng như đã nêu có những mâu thuẫn trong việc bảo hộ quyền tác giả và sự phát triển của internet.

Bài viết phân tích những rào cản trong quy định về bảo hộ quyền tác giả đối với truy cập mở và tài nguyên giáo dục mở.
\end{abstract}

Tù khóa: Quyền tác giả, Truy cập mở, Tài nguyên giáo dục mở.

\section{Sự cần thiết của truy cập mở và tài nguyên giáo dục mở}

Công nghệ in ấn ra đời làm cho việc sao chép tác phẩm trở nên dễ dàng và nhanh chóng, dẫn đến xuất hiện việc sao chép trái phép tác phẩm, bởi vậy cần ban hành quy định để chống lại việc sao chép trái phép này, từ đó hình thành pháp luật về bảo hộ quyền tác giả.

Tại Trung Quốc vào thời nhà Đường, công nghệ in khắc gỗ đã được sử dụng, nhưng công

\footnotetext{
*ĐT.: 84-903211972.

Email: tranhailinhvn@yahoo.com

https://doi.org/10.25073/2588-1116/vnupam.4111
}

nghệ in ấn này phải chi phí rất lớn và mất nhiều thời gian. Đến thời nhà Tống $(960$ - 1279), Tất Thăng (Bi Sheng 990-1051) đã sáng chế ra chữ rời (hoạt tự) từ nguyên liệu đất sét (gốm), làm cho việc in ấn trở nên nhanh chóng và dễ dàng hơn. Công nghệ in ấn này đã truyền sang Triều Tiên, Nhật Bản, sau đó thông qua Đế quốc Mông Cổ, nó được truyền sang phương Tây, đẩy mạnh việc giao lưu văn hóa giữa các châu lục [1]. Tuy nhiên, công nghệ in ấn theo sáng chế của Tất Thăng vẫn thuộc dạng thủ công, chi phí cao, tốc độ in chậm, do đó việc sao chép trái phép tác phẩm chưa diễn ra nhiều.

Năm 1450, khi Johannes Gutenberg người Đức sáng chế ra công nghệ máy in [2], thì việc 
sao chép tác phẩm trở nên dễ dàng, nhiều tác phẩm chuyển tải sự sáng tạo của con người bị sao chép bất hợp pháp. Từ thực tế này, đòi hỏi pháp luật phải được ban hành để điều chỉnh việc chống lại sự sao chép bất hợp pháp các tác phẩm. Như vậy, pháp luật về quyền tác giả ra đời có nguyên nhân từ sự tác động của công nghệ, mà cụ thể là công nghệ in ấn.

Đạo luật về Quyền tác giả đầu tiên trên Thế giới có hiệu lực vào năm 1710 tại Anh quốc (The Statute of Anne of 1710) [3], đã quy định tác giả của một tác phẩm có 14 năm độc quyền in ấn hoặc cho phép in ấn tác phẩm đó và độc quyền này có thể được gia hạn thêm 14 năm nữa, nếu tác giả vẫn còn sống khi thời hạn bảo hộ lần đầu đã hết hiệu lực.

Công ước Berne (1886) về bảo hộ các tác phẩm văn học và nghệ thuật cũng ghi nhận quyền sao chép là một bộ phận của quyền tác giả. Cùng với sự phát triển của khoa học và công nghệ, khái niệm sao chép tác phẩm được mở rộng hơn, phiên bản Công ước Berne (September 28, 1979) đã đưa ra thuật ngữ "tái tạo tác phẩm" khi quy định về quyền tác giả tại Điều 9.1. Tác giả có các tác phẩm văn học nghệ thuật được Công ước này bảo hộ, được độc quyền cho phép tái tạo lại các tác phẩm đó dưới bất kỳ phuoong thức hay hình thức nào. Việc sử dụng thuật ngữ "tái tạo tác phẩm" có nghĩa rộng hơn "bản sao, bản in tác phẩm", vì "tái tạo tác phẩm" còn có thể điều chỉnh được quy định quyền cho phép làm tác phẩm phái sinh (ví dụ dịch tác phẩm, chuyển thể tác phẩm từ hình thức thể hiện này sang hình thức thể hiện khác - như chuyển thể tác phẩm văn học sang kịch bản điện ảnh...) [4]. ${ }^{2}$

\footnotetext{
${ }^{1}$ Khong Dennis W. K. (2006). The Historical Law and Economics of the First Copyright Act. Erasmus Law and Economics Review 2, No. 1 (March 2006): 35-69, cho rằng đạo luật về quyền tác giả đầu tiên trên thế giới ghi nhận quyền tác giả thực chất là quyền sao chép tác phẩm và quyền này gắn với yếu tố kinh tế.

${ }^{2}$ Bản dịch Các Công uớc và Hiệp uoóc quốc tế về quyè̀n tác giả do Cục Bản quyền tác giả xuất bản tháng 12.2000 tại Hà Nội đã dịch Điều 9.1 là Tác giả có các tác phẩm văn hoc nghệ thuật được Công ước này bảo hộ, được toàn quyền cho phép sao in các tác phẩm đó duóoi bất kỳ
}

Với sự phát triển của công nghệ, đặc biệt là sự ra đời của internet đã tác động không nhỏ đến lĩnh vực quyền tác giả, internet có thể giúp tác giả đưa tác phẩm của mình tới công chúng một cách thuận tiện, nhanh chóng. Nhưng internet cũng cho phép các hành vi sao chép trái phép tác phẩm, gây phương hại đến quyền tài sản của chủ sở hữu tác phẩm, cùng với đó thuật ngữ "quyền sao chép tác phẩm" hay "quyền tái tạo tác phẩm|" theo cách hiểu cũ có thể là rào cản trong việc bảo hộ và thực thi quyền tác giả (trong đó có quyền sao chép).

Trong lĩnh vực nghiên cứu khoa học, việc nhanh chóng chia sẻ kết quả nghiên cứu là cần thiết, nó giúp ích cho sự phát triển của khoa học và công nghệ $(\mathrm{KH} \& \mathrm{CN})$, từ đó hình thành nhu cầu "truy cập mở" (Open Access). Trong lĩnh vực giáo dục và đào tạo, việc nhanh chóng đưa tri thức $\mathrm{KH} \& \mathrm{CN}$ vào trường học là việc làm cấp bách, từ đó hình thành nhu cầu về "tài nguyên giáo dục mở" (Open Educational Resources). Truy cập mở và tài nguyên giáo dục mở không thể tách rời công cụ truy cập là internet, nhưng như đã nêu có những mâu thuẫn trong việc bảo hộ quyền tác giả và sự phát triển của internet.

Tại Việt Nam, theo khảo sát của Cao Minh Kiểm, Đinh Thị Thúy Quỳnh, Nguyễn Thị Thưa, Lưu Xuân Xa (2017), cho thấy ngoài cơ sở dữ liệu nhiệm vụ KH\&CN Việt Nam do Cục Thông tin KH\&CN Quốc gia xây dựng thì việc thu thập, đăng ký kết quả thực hiện các nhiệm vụ KH\&CN tại các sở KH\&CN cấp tỉnh và một số trường đại học vẫn còn hạn chế. Đồng thời việc số hóa các loại tài liệu này chưa được xử lý đầy đủ, đồng bộ và thống nhất giữa các tỉnh,

phưong thức hay hình thức nào. Tác giả (TVH) đã tham khảo Điều 9.1 trong nguyên gốc tiếng Anh: "Authors of literary and artistic works protected by this Convention shall have the exclusive right of authorizing the reproduction of these works, in any manner or form" và cho rằng "exclusive right" nên dịch là "độc quyền" để nhấn mạnh tính duy nhất, đồng thời thuật ngữ "reproduction" nên dịch là "tái tạo". Để có cơ sở đưa ra nhận định này, xin tham khảo thêm tài liệu của WIPO (2009). Understanding Copyright and Related Rights. Publication No. 909(E) ISBN 978-92-805-1265-6, trong đó đã đưa ra thuật ngữ "Rights of reproduction". 
dẫn đến việc chưa có cơ sở dữ liệu để tra cứu các nhiệm vụ KH\&CN đang thực hiện và các nhiệm vụ KH\&CN đã nghiệm thu. Tại các trường đại học, website thư viện đã được xây dựng và đưa vào phục vụ nhưng việc phát triển các website này còn nhiều bất cập... cơ sở dữ liệu số hóa nếu có thì đa phần mới chỉ dừng lại ở danh mục hoặc bản tóm tắt các đề tài đã nghiệm thu [5].

Như vậy, việc nghiên cứu để tìm ra những nguyên nhân dẫn đến các hiện tượng như đã nêu là cần thiết. Bài viết này phân tích rào cản trong quy định về bảo hộ quyền tác giả đối với truy cập mở và tài nguyên giáo dục mở, như là một trong các nguyên nhân cần tìm.

\section{Quy định quốc tế về truy cập mở}

\subsection{Sáng kiến Budapest}

Thuật ngữ "truy cập mở" (Open Access) lần đầu tiên được công bố trong văn kiện Sáng kiến truy cập mở Budapest (Budapest Open Access Initiative -2002$)^{3}$ - gọi tắt là Sáng kiến Budapest.

Sáng kiến Budapest cho rằng bằng công cụ truy cập mở miễn phí trên internet công cộng, cho phép người dùng đọc, tải xuống, sao chép, phân phối, in ấn toàn văn các tài liệu, chuyền chúng như dữ liệu sang phần mềm hoặc sử dụng chúng cho bất kỳ mục đích hợp pháp nào khác mà không có các rào cản về tài chính, pháp lý hoặc kỹ thuật. Điểm lưu ý duy nhất về truy cập mở là phải đảm bảo các quyền nhân thân của tác giả, trong đó nhấn mạnh đến quyền đứng tên đối với tác phẩm, quyền đặt tên cho tác phẩm và quyền bảo vệ sự toàn vẹn của tác phẩm.

\footnotetext{
$\overline{3}$ Ý tưởng về truy cập mở được hình thành từ cuộc cuộc họp do Open Society Institute triệu tập tại Budapest, Hungary vào ngày 01 và 02 tháng 12 năm 2001, sau đó Sáng kiến truy cập mở Budapest được công bố vào ngày 14.02.2002, với các nguyên tắc liên quan đến việc truy cập mở đối với các tài liệu nghiên cứu (research literature), vào thời điểm đó còn được gọi là Học bổng trực tuyến miễn phí (Free Online Scholarship).
}

Chỉ tính đến 14.02.2002 đã có 5932 cá nhân và 837 tổ chức đã đồng ý tham gia Sáng kiến Budapest, đưa các kết quả nghiên cứu của mình lên internet qua công cụ truy cập mở [6].

\subsection{Tuyên bố Bethesda}

Tiếp theo đó, Tuyên bố Bethesda về xuất bản truy cập mở (Bethesda Statement on Open Access Publishing) - gọi tắt là Tuyên bố Bethesd ${ }^{4}$.

Ngày 11.4.2003, Viện Y khoa Howard Hughes đã tổ chức cuộc họp để thảo luận về quyền tiếp cận các tài liệu học thuật, cuộc họp đã đưa ra định nghĩa về "Tạp chí truy cập mở" (Open Access Journal - OAJ), đề cập đến việc cấp quyền truy cập, quyền sao chép, sử dụng, phân phối, truyền tải và hiển thị tác phẩm khoa học - là kết quả nghiên cứu một cách công khai, miễn phí trên phạm vi toàn cầu. Cần phải thấy rằng, theo nguyên tắc bảo hộ tự động đối với tác phẩm nói chung, trong đó có tác phẩm khoa học theo quy định của Công ước Berne 1886, tại thời điểm một tác phẩm khoa học được công bố tại một quốc gia thành viên, thì ngay lập tức và vô điều kiện, nó phải được tất cả các quốc gia thành viên còn lại bảo hộ. Một trong những nội dung bảo hộ là bảo hộ quyền sao chép tác phẩm khoa học, như vậy cụm từ "miễn phí trên phạm vi toàn cầu" nêu trên được xem là yếu tố rất mạnh của Tuyên bố Bethesda.

Đặc biệt, trong khi Sáng kiến Budapest chưa đề cập đến việc thực hiện và phân phối các tác phẩm phái sinh, thì OAJ đã cho phép thực hiện tác phẩm phái sinh từ các tác phẩm gốc thông qua công cụ truy cập mở, có nghĩa rằng người truy cập mở có quyền dịch tác phẩm gốc sang một ngôn ngữ khác, có quyền đưa tác phẩm gốc vào bộ sưu tập... phục vụ mục đích nghiên cứu. Điểm tiến bộ hơn nữa, Tuyên bố Bethesda còn đảm bảo cho phép người truy cập mở có quyền tái sử dụng kết quả nghiên cứu ( $a$ license granting rights for reuse). Như vậy, với Tuyên bố Bethesda, người nghiên cứu có quyền truy cập mở để tiếp cận các kết quả nghiên cứu

\footnotetext{
$\overline{4}$ Bethesda là một thành phố thuộc bang Maryland, Hoa Kỳ
} 
đã công bố, sử dụng chúng vào mục đích nghiên cứu của mình.

Một điểm nữa cũng cần nhắc đến, Tuyên bố Bethesda không nêu nghĩa vụ về tài sản của người nghiên cứu khi sử dụng kết quả nghiên cứu đã công bố thông qua truy cập mở, phải chia sẻ thu nhập (nếu có) từ kết quả nghiên cứu của mình cho tác giả của các kết quả nghiên cứu đã công bố, mà chỉ quy định nghĩa vụ phải đảm bảo quyền nhân thân đối với tác giả của các kết quả nghiên cứu đã công bố.

\subsection{Tuyên bố Berlin}

Tuyên bố Berlin về truy cập mở đối với kiến thức khoa học và nhân văn (Berlin Declaration on Open Access to Knowledge in the Sciences and Humanities) - gọi tắt là Tuyên bố Berlin 5 .

Tuyên bố Berlin đã mở ra quyền truy cập mở kể cả đối với những kiến thức trong lĩnh vực khoa học xã hội và nhân văn (XH\&NV). Ngoài việc công nhận các quyền như Sáng kến Budapest và Tuyên bố Bethesda đã nêu, Tuyên bố Berlin có điểm đáng lưu ý, đó là những người truy cập mở có quyền tạo ra một số lượng nhỏ các bản sao in cho mục đích sử dụng cá nhân của họ (the right to make small numbers of printed copies for their personal use).

Như vậy, trong khi pháp luật về quyền tác giả của nhiều quốc gia (trong đó có Việt Nam) chỉ cho phép người sử dụng "tự sao chép một bản nhằm mục đích nghiên cứu khoa học, giảng dạy của cá nhân" như quy định tại Điều 25.1.a. Luật SHTT Việt Nam, thì Tuyên bố Berlin đã mở rộng hơn, cho phép người truy cập mở có quyền tạo ra một số lượng nhỏ các bản sao in cho mục đích sử dụng cá nhân của họ, tuy nhiên Tuyên bố Berlin không định nghĩa định lượng cụm từ "số lượng nhỏ". Điểm nữa cần lưu ý, cụm từ "mục đích sử dụng cá nhân của họ" có

\footnotetext{
${ }^{5}$ Tuyên bố Berlin được soạn thảo tại Hội nghị do Hiệp hội Max Planck và dự án European Cultural Heritage Online tổ chức vào tháng 10.2003, Hội nghị này có hơn 120 tổ chức văn hóa và chính trị từ khắp nơi trên thế giới tham dự.
}

nội hàm rộng hơn cụm từ "mục đích nghiên cứu khoa học, giảng dạy của cá nhân".

Điểm cần phải bàn sâu thêm về nội dung của Tuyên bố Berlin, khi cho phép truy cập mở đối với các kết quả nghiên cứu trong lĩnh vực khoa học XH\&NV, như đã biết kết quả nghiên cứu trong lĩnh vực khoa học XH\&NV không phải là đối tượng của sáng chế, do đó quyền tài sản đối với kết quả nghiên cứu trong lĩnh vực khoa học XH\&NV thường tập trung chủ yếu vào quyền sao chép, quyền cho làm tác phẩm phái sinh, mà nội dung của Tuyên bố Berlin lại bao hàm cả hai quyền này. Cần phải thấy rằng, nếu mỗi người đều có quyền thông qua công cụ truy cập mở để tạo ra một số lượng nhỏ các bản sao in cho mục đích sử dụng cá nhân của họ, thì chắc chắn thu nhập của tác giả/chủ sở hữu tác phẩm thông qua việc xuất bản bản in sẽ giảm. Qua đây cho thấy ý nghĩa nhân văn, vì sự phát triển của $\mathrm{KH} \& \mathrm{CN}$ do Tuyên bố Berlin đưa ra.

\section{Quy định quốc tế về tài nguyên giáo dục mỏ}

Tài nguyên giáo dục mở (Open Educational Resources) viết tắt là OER. Quỹ Hewlett Foundation (2002) định nghĩa: OER là tài liệu giáo dục được cấp phép (licensed) miễn phí và công khai, được sử dụng cho mục đích giảng dạy, học tập, nghiên cứu và các mục đích khác. ${ }^{6}$

OECD (2007) định nghĩa OER là các tài liệu được số hóa, cung cấp tự do và công khai cho giảng viên, sinh viên và người học tự học để sử dụng và tái sử dụng cho mục đích giảng dạy, học tập và nghiên cứu [7]. Công cụ để phát triển, sử dụng, phân phối nội dung và thực hiện OER là giấy phép mở (licences) .

Xin lưu ý, cả hai định nghĩa của Hewlett Foundation (2002) và của OECD (2007) đều

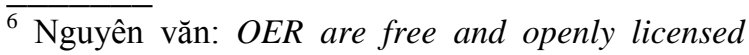
educational materials that can be used for teaching, learning, research, and other purposes. Trong định nghĩa này của Hewlett Foundation (2002) có một thuật ngữ rất khó hiểu: "other purposes", có lẽ mục đích khác mà Hewlett Foundation nhắc đến không bao gồm mục đích thương mại.
} 
nhắc đến sự tồn tại của OER phải trên cơ sở được cấp phép như bài viết đã gạch chân 2 cụm từ này để nhấn mạnh.

Về thuật ngữ license, hiện có 2 cách dùng [8]:

- Trong tiếng Anh Mỹ (American English), License dùng với nghĩa danh từ (giấy phép) và với cả nghĩa động từ (cấp phép), với lưu ý trong American English không tồn tại thuật ngữ Licence. $^{7}$

- Trong tiếng Anh, Licence với nghĩa danh từ (giấy phép) và License với nghĩa động từ (cấp phép) ${ }^{8}$.

Trong lĩnh vực quyền tác giả: License được dùng với nghĩa chuyển quyền sử dụng quyền tác giạ ${ }^{9}$, Khoản 1 Điều 47 Luật Sở hữu trí tuệ (SHTT) định nghĩa: chuyển quyền sử dụng quyền tác giả là việc chủ sở hữu quyền tác giả cho phép tổ chức, cá nhân khác sử dụng có thời hạn một, một số hoặc toàn bộ các quyền trong quyền tác giả.

Như vậy, điều kiện để tồn tại OER là:

- Phải được sự cho phép của chủ sở hữu tác phẩm khoa học; quyền.

- Sự cho phép là có giới hạn về thời gian, về

Vấn đề khó nhất để tồn tại OER là chủ thể nào có quyền cho phép? Nói cách khác, cần xác định chủ thể nào là tác giả của tác phẩm khoa học bao gồm sách giáo khoa, bài giảng, sách tham khảo, sách chuyên khảo, khóa luận, luận văn, luận án, bài báo khoa học, đề tài khoa học...?

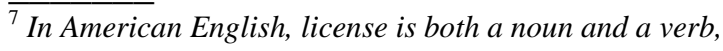
and licence isn't used

${ }^{8}$ Licence is the noun, and license is the verb.

${ }^{9}$ Bản tiếng Anh của Luật SHTT Việt Nam do WIPO lưu giữ cũng dùng Licensing of Copyright để chỉ việc chuyển quyền sử dụng quyền tác giả.
}

\section{Chính sách của một số tổ chức quốc tế, quốc gia về truy cập mở và tài nguyên giáo dục mở}

\subsection{Chính sách của OECD}

Tháng 01.2004, Hội nghị Bộ trưởng KH\&CN các nước OECD, Trung Quốc, Israel, Nga và Nam Phi đã họp tại Paris để thảo luận nhu cầu quốc tế về tiếp cận dữ liệu nghiên cứu. Hội nghị đã thông qua Tuyên bố về truy cập dữ liệu nghiên cứu từ tài trợ công (Declaration on Access to Research Data from Public Funding), trong đó công nhận tầm quan trọng của việc tiếp cận các dữ liệu nghiên cứu ở quy mô toàn cầu và đề nghị $\mathrm{OECD}$ xây dựng một bộ hướng dẫn nguyên tắc chung để tạo điều kiện thuận lợi nhất cho việc truy cập dữ liệu nghiên cứu từ nguồn tài trợ công.

Từ tuyên bố của Hội nghị Bộ trưởng $K H \& C N$ các nước $\mathrm{OECD}$ và các quốc gia trên, OECD đã ban hành nguyên tắc và hướng dẫn về truy cập dữ liệu nghiên cứu từ tài trợ công [9].

Trong văn bản này, $\mathrm{OECD}$ đã định nghĩa dữ liệu nghiên cứu (Research data)

và dữ liệu nghiên cứu từ tài trợ công (Research data from public funding), đồng thời đưa ra các nguyên tắc truy cập dữ liệu nghiên cứu, trong đó nhấn mạnh đến nguyên tắc cởi mở (Openness), linh hoạt (Flexibility), minh bạch (Transparency), phù hợp về luật pháp (Legal conformity), bảo hộ sở hữu trí tuệ (Protection of intellectual property), trách nhiệm chính thức (Formal responsibility), chuyên nghiệp (Professionalism), khả năng tương tác (Interoperability), chất lượng (Quality), an ninh (Security), hiệu quả (Efficiency), giải trình (Accountability), bền vững (Sustainability).

OECD cũng nhấn mạnh rằng việc truy cập mở đối với dữ liệu nghiển cứu từ nguồn tài trợ công sẽ thúc đẩy sự phát triển của $\mathrm{KH} \& \mathrm{CN}$ nói chung trên phạm vi toàn cầu, tiết kiệm chi phí trong nghiên cứu. 


\subsection{Chính sách chung của $G 8$}

Ngày 18.6.2013 các nhà lãnh đạo G8 đã ký Hiến chương dữ liệu mở (Open Data Charter) [10], Hiến chương này đã mở ra 5 nguyên tắc chiến lược mà tất cả các thành viên $\mathrm{G} 8$ sẽ hành động, với kỳ vọng rằng tất cả dữ liệu nghiên cứu từ nguồn tài chính của chính phủ sẽ được công bố một cách công khai, cùng với các nguyên tắc để tăng chất lượng, số lượng và tái sử dụng dữ liệu nghiên cứu được công bố.

Các thành viên G8 cũng xác định được dũ liệu nghiên cứu từ 14 lĩnh vực, trong đó có dữ liệu nghiên cứu về quản trị kinh doanh, tội phạm và tư pháp, khoa học trái đất, giáo dục, năng lượng và môi trường, tài chính và hợp đồng, không gian địa lý (geospatial), phát triển toàn cầu, trách nhiệm giải trình và dân chủ (government accountability and democracy), sức khỏe, nghiên cứu khoa học, số liệu thống kê, di động xã hội và phúc lợi (social mobility and welfare), giao thông và cơ sở hạ tầng là các lĩnh vực được chia sẻ thông tin dữ liệu nghiên cứu qua công cụ truy cập mở.

\subsection{Chính sách của Canada}

Về kết quả nghiên cứu trong 20 lĩnh vực KH\&CN được thể hiện qua tác phẩm The State of Science and Technology in Canada, 2012 [11] cho thấy thế mạnh về KH\&CN của Canada ở tất cả các lĩnh vực khác nhau. Sau đây chỉ xin khảo sát 3 lĩnh vực khoa học được công bố trong tác phẩm này:

- Về nông nghiệp, thủy sản và lâm nghiệp: có các kết quả nghiên cứu với chỉ số trích dẫn được xếp hạng thứ hai trên toàn thế giới (It is ranked second in the world by top-cited international researchers, the highest of all fields), tổng số nghiên cứu sinh quốc tế đến từ các quốc gia khác nhau trên thế giới tốt nghiệp bậc tiến sĩ về khoa học thuộc lĩnh vực nông nghiệp, thủy sản và lâm nghiệp chiếm $23 \%$ số nghiên cứu sinh tốt nghiệp tiến sĩ ở 20 lĩnh vực khác nhau tại Canada;

- Về sinh học: có các kết quả nghiên cứu với chỉ số trích dẫn được xếp hạng thứ tư trên toàn thế giới. Ba tiểu lĩnh vực (sub-fields) trong sinh học mà Canada có thế mạnh đặc biệt là sinh học tiến hóa (Evolutionary Biology), điểu học (Ornithology) và động vật học (Zoology). Trong đó điểu học là một tiểu lĩnh vực lớn chiếm đến $8,8 \%$ kết quả nghiên cứu của toàn thế giới trong giai đoạn 2005-2010, tiếp đến là sinh học tiến hóa cũng chiếm đến $6,9 \%$ kết quả nghiên cứu trên toàn thế giới trong giai đoạn 2005-2010;

- Về hóa học: có các kết quả nghiên cứu với chỉ số trích dẫn được xếp hạng thứ bảy trên toàn thế giới.

Để có thể công bố kết quả nghiên cứu một cách nhanh chóng và thuận tiện, Canada ban hành Đạo luật truy cập thông tin (Access to Information Act) có hiệu lực từ 1983, tuyên bố rằng công chúng có quyền truy cập thông tin của chính phủ, trừ những trường hợp ngoại lệ hạn chế quyền truy cập, tuy nhiên những ngoại lệ này phải nằm trong danh mục theo quy định của pháp luật.

Thực hiện Chiến lược truy cập mở đối với khoa học, công nghệ và đổi mới của Canada 2014 (Open Access Canada's Science, Technology and Innovation Strategy), Hội đồng Nghiên cứu Khoa học Tự nhiên và Kỹ thuật (Natural Sciences and Engineering Research Council), Hội đồng Nghiên cứu Khoa học XH\&NV (Social Sciences and Humanities Research Council) và Viện nghiên cứu $\mathrm{Y}$ tế Canada (Canadian Institutes for Health Research) đã ra tuyên bố cam kết rằng các kết quả của nghiên cứu được tài trợ bởi chính phủ liên bang phải được cho phép truy cập mở trong vòng 12 tháng sau khi công bố. ${ }^{10}$

\subsection{Chính sách của Nhật Bản}

Nhật Bản là quốc gia có tiềm lực khoa học mạnh, là quốc gia sở hữu bằng độc quyền sáng chế đứng thứ hai trên thế giới, theo công bố của Cơ quan Sáng chế và Nhãn hiệu Hoa Kỳ

\footnotetext{
${ }^{10}$ Nguyên văn: ... requiring that the results of federally funded research be made available within 12 months of publication.
} 
(United States Patent and Trademark Office's USPTO) thì tính từ 01/01/1977 đến 31/12/2014, Hoa Kỳ đứng đầu thế giới với 5.413.873 patent, vị trí thứ hai là Nhật Bản với 1.014.977 patent [12].

Ngay từ năm 2004, Nhật Bản đã thực hiện Chương trình phát triển nguồn tài nguyên số và truy cập mở, do Viện Thông tin Quốc gia (National Institute of Informatics - NII) chủ trì thực hiện. Chương trình này giúp Nhật Bản có những bước tiến trong việc liên kết và công bố thông tin khoa học. NII đã triển khai và xây dựng Cơ sở hạ tầng mạng khoa học (Cyber Science Infrastructure), làm cơ sở cho việc trao đổi thông tin $\mathrm{KH} \& \mathrm{CN}$ giữa các nhà nghiên cứu, đây là hệ thống chính cho môi trường thông tin đại học, có sự hợp tác đa dạng về những hoạt động nghiên cứu, phổ biến thông tin số hóa từ các trường đại học và các viện nghiên cứu [5].

Bên cạnh đó, dự án Truy cập mở Nhật Bản (Open Access Japan), do Hiệp hội Khuyến khích khoa học Nhật Bản (Japan Society for the Promotion of Science) tài trợ, đã tiến hành các nghiên cứu có liên quan:

- Nghiên cứu tích hợp chuyển đổi truyền thông học thuật trong truy cập mở (Integrated Research on Transformation of Scholarly Communication in Open Access Movement) do Keiko KURATA, Đại học Keio chủ trì thực hiện;

- Tái cấu trúc lại các chức năng của các thư viện nghiên cứu trong môi trường số (Reengineering of the Functionalities of Research Libraries in the Digital Milieu) do Syun TUTIYA , Đại học Chiba chủ trì thực hiện.

Hai nhóm nghiên cứu trên cùng có chung ý kiến khi cho truy cập mở và tài nguyên số là cần thiết và là hình thức để tiết kiệm các nguồn lực, trong đó có nguồn lực về tài chính, về thời gian, về trí tuệ để kết nối những người nghiên cứu, trao đổi kết quả nghiên cứu nhẳm thúc đẩy sự phát triển của $\mathrm{KH} \& \mathrm{CN}$, hai nhóm nghiên cứu cũng khẳng định truy cập mở và tài nguyên số cần thiết phải được chia sẻ trên phạm vi toàn cầu.

\section{Quy định của pháp luật Việt Nam về quyền tác giả đối với OER}

\subsection{Tác phẩm khoa học}

Giới hạn của quyền tác giả trong mục này:

- Quyền sao chép: quyền quan trọng nhất trong nhóm quyền tài sản đối với tác phẩm;

- Tác phẩm: chỉ đề cập đến phẩm khoa học. Tác phẩm khoa học có thể gồm: sách giáo khoa, bài giảng, sách tham khảo, sách chuyên khảo, khóa luận, luận văn, luận án, bài báo khoa học, đề tài khoa học...

Điều 8 Nghị định 100/2006/NĐ-CP quy định: Tác giả là người trục tiếp sáng tạo ra một phần hoạc toàn bộ tác phẩm văn học, nghệ thuật và khoa hoc, đồng thời nghị định này không quy định tác giả là pháp nhân, do đó có thể nói rằng tác giả chỉ có thể là cá nhân. Trong trường hợp cụ thể này, tác giả bài giảng, giáo trình, sách tham khảo là giảng viên/những giảng viên.

\subsection{Khóa luận (đồ án), luận văn, luận án}

Điều 38 Luật Giáo dục đại học quy định về khóa luận, luận văn, luận án, có thể hiểu như sau:

- Sinh viên hoàn thành chương trình đào tạo cao đẳng, có đủ điều kiện thì được dự thi tốt nghiệp hoặc bảo vệ chuyên đề, khóa luận tốt nghiệp. Chuyên đề, khóa luận tốt nghiệp cao đẳng chuyển tải kiến thức chuyên môn cơ bản, kỹ năng thực hành thành thạo, hiểu biết được tác động của các nguyên lý, quy luật tự nhiên xã hội trong thực tiễn và có khả năng giải quyết những vấn đề thông thường thuộc ngành được đào tạo;

- Sinh viên hoàn thành chương trình đào tạo đại học, có đủ điều kiện thì được dự thi tốt nghiệp hoặc bảo vệ đồ án, khóa luận tốt nghiệp. Đồ án, khóa luận tốt nghiệp chuyển tải kiên thức chuyên môn toàn diện, để chứng minh sinh viên nắm vững nguyên lý, quy luật tự nhiên - xã hội, có kỹ năng thực hành cơ bản, có khả năng làm việc độc lập, sáng tạo và giải quyết những vấn đề thuộc ngành được đào tạo; 
- Học viên hoàn thành chương trình đào tạo thạc sĩ, có đủ điều kiện thì được bảo vệ luận văn. Luận văn thạc sĩ chuyển tải kiến thức khoa học nền tảng, nhằm chứng minh học viên có kỹ năng chuyên sâu cho nghiên cứu về một lĩnh vực khoa học hoặc hoạt động nghề nghiệp có hiệu quả, có khả năng làm việc độc lập, sáng tạo và có năng lực phát hiện, giải quyết những vấn đề thuộc chuyên ngành được đào tạo;

- Nghiên cứu sinh hoàn thành chương trình đào tạo tiến sĩ, có đủ điều kiện thì được bảo vệ luận án. Luận án tiến sĩ chuyển tải kiến thức ở trình độ cao về lý thuyết và ứng dụng, chứng minh nghiên cứu sinh có năng lực nghiên cứu độc lập, sáng tạo, phát triển tri thức mới, phát hiện nguyên lý, quy luật tự nhiên - xã hội và giải quyết những vấn đề mới về khoa học, công nghệ, hướng dẫn nghiên cứu khoa học và hoạt động chuyên môn.

\subsection{Tác giả khóa luận (đồ án), luận văn, luận án}

Đối với khóa luận tác giả là sinh viên, luận văn tác giả là học viên cao học và luận án tiến sĩ tác giả là nghiên cứu sinh.

Trong quá trình thực hiện khóa luận, luận văn, luận án, tác giả của chúng được sự hướng dẫn của người hướng dẫn khoa học. Người hướng dẫn khoa học có thể là giảng viên cơ hữu của cơ sở đào tạo hoặc cũng có thể là người có trình độ chuyên môn ở ngoài cơ sở đào tạo được cơ sở đào tạo mời hướng dẫn cho sinh viên, học viên, nghiên cứu sinh thực hiện khóa luận, luận văn, luận án.

Khoản 2 điều 8 Nghị định 100/2006/NĐ-CP quy định: Tổ chức, cá nhân làm công việc hỗ trợ, góp ý kiến hoặc cung cấp tư liệu cho người khác sáng tạo ra tác phẩm không được công nhận là tác giả. Như vậy, chỉ có sinh viên mới được công nhận là tác giả khóa luận đại học/cao đẳng, học viên cao học là tác giả luận văn thạc sĩ, nghiên cứu sinh là tác giả của luận án tiến sĩ, người hướng dẫn khoa học không được công nhận là đồng tác giả của khóa luận, luận văn, luận án.

\section{4. Đề tài nghiên cứu khoa học}

Khoản 4 điều 3 Luật Khoa học và Công nghệ quy định: Nghiên cứu khoa học là hoạt động khám phá, phát hiện, tìm hiểu bản chất, quy luật của sự vật, hiện tượng tự nhiên, xã hội và tư duy; sáng tạo giải pháp nhằm ứng dụng vào thực tiễn.

Theo Vũ Cao Đàm [13] thì nghiên cứu cơ bản là những nghiên cứu nhằm phát hiện thuộc tính, cấu trúc, động thái của sự vật. Kết quả nghiên cứu cơ bản có thể là các khám phá, phát hiện, phát minh, dẫn tới hình thành một hệ thống lý thuyết mới.

Nội dung của kết quả nghiên cứu cơ bản không được bảo hộ theo pháp luật về sáng chế, nhưng bản viết về nó lại là tác phẩm khoa học và được bảo hộ theo quy định tại điều 14.1.a. Luật Sở hữu trí tuệ (SHTT) và điều 2.1. Công ước Berne về bảo hộ các tác phẩm văn học và nghệ thuật ${ }^{11}$.

\subsection{Tác giả đề tài nghiên cứu khoa học}

Tác giả đề tài nghiên cứu khoa học có thể là cá nhân/những cá nhân hay có thể nói cách khác có tác giả và đồng tác giả đề tài nghiên cứu khoa học. Vai trò của tác giả trong đề tài nghiên cứu khoa học là khác nhau:

- Chủ nhiệm đề tài: Là người nghiên cứu cũng đồng thời là người điều hành trong quá trình thực hiện đề tài nghiên cứu khoa học.

- Thư ký đề tài: là người giúp cho chủ nhiệm đề tài trong các công việc chuyên môn hoặc hành chính liên quan đển đề tài.

- Người tham gia thực hiện đề tài: Theo sự phân công của chủ nhiệm đề tài, những người tham gia thực hiện đề tài thường là những người có chuyên môn sâu trong lĩnh vực nghiên cứu.

\footnotetext{
${ }^{11}$ Xin tham khảo thêm: Trần Văn Hải, Bàn về các thuật ngũu "phát minh", "phát hiện", "sáng chế". Tạp chí Hoạt động khoa học,số 6.2007 (577), tr. 26 - 28.
} 


\subsection{Chủ sở hũu của kết quả nghiên cứu khoa học}

Trong hoạt động nghiên cứu khoa học, việc xác định chủ sở hữu kết quả nghiên cứu không chỉ có ý nghĩa trong việc thương mại hóa kết quả nghiên cứu mà còn có ý nghĩa đối với danh dự và uy tín của tác giả - người sáng tạo ra kết quả nghiên cứu.

Điều 26 Luật KH\&CN quy định: Tổ chức, cá nhân đầu tư cho việc thực hiện nhiệm vụ $\mathrm{KH} \& \mathrm{CN}$ là chủ sở hữu kết quả nghiên cứu khoa học và phát triển công nghệ; tổ chức, cá nhân trực tiếp thực hiện công trình $\mathrm{KH} \& \mathrm{CN}$ là tác giả của công trình đó, trừ trường hợp các bên có thoả thuận khác trong hợp đồng KH\&CN.

Về nguyên tắc, tổ chức hoặc cá nhân đầu tư tài chính, cơ sở vật chất để cho các cá nhân tạo ra kết quả nghiên cứu khoa học thì là chủ sở hữu quyền tác giả.

Việc phân định giữa tác giả và chủ sở hữu quyền tác giả có ý nghĩa rất quan trọng trong việc xác định các quyền nhân thân và quyền tài sản theo pháp luật. Trên cơ sở đó xác định chủ thể nào có quyền đăng ký (nếu bắt buộc) và khai thác tài sản trí tuệ đã được tạo ra. Thông thường chủ sở hữu quyền tác giả đối với kêt quả nghiên cứu khoa học trong những trường hợp sau:

- Chủ sở hữu quyền tác giả kết quả nghiên cứu khoa học là tổ chức: Tổ chức này đã đầu tư tài chính, cơ sở vật chất - kỹ thuật (có thể dùng ngân sách Nhà nước hoặc không dùng ngân sách nhà nước) cho cá cá nhân khác thực hiện việc nghiên cứu theo đơn đặt hàng hoặc hợp đồng nghiên cứu giữa các bên.

- Chủ sở hữu quyền tác giả kết quả nghiên cứu khoa học là cá nhân (không đồng thời là tác giả): Cá nhân đã đầu tư tài chính, cơ sở vật chất - kỹ thuật cho cá cá nhân khác thực hiện việc nghiên cứu theo đơn đặt hàng hoặc hợp đồng nghiên cứu giữa các bên.

- Chủ sở hữu quyền tác giả là cá nhân đồng thời là tác giả của kết quả nghiên cứu khoa học: Nếu tác giả sử dụng thời gian, tài chính, cơ sở vật chất - kỹ thuật của mình để sáng tạo ra tác phẩm khoa học thì tác giả là chủ sở hữu tác phẩm này.

Trường hợp giữa tổ chức hoặc cá nhân đầu tư một phần tài chính, cơ sở vật chất và tác giả cũng đầu tư một phần tài chính thì xác định chủ sở hữu quyền tác giả trên cơ sở thỏa thuận của các bên.

Chủ sở hữu có quyền công bố tác phẩm khoa học, đồng thời có toàn bộ nhóm quyền tài sản được quy định tại điều 20 của Luật SHTT [14].

Tuy nhiên, quy định trên đây chưa giải quyết được các trường hợp cụ thể: kết quả nghiên cứu là sự sáng tạo của nhiều tác giả với các mức độ đóng góp khác nhau; kết quả nghiên cứu do nhiều người đầu tư tài chính để thực hiện ở các giai đoạn khác nhau; kết quả nghiên cứu vừa được bảo hộ theo pháp luật về quyền tác giả, vừa được bảo hộ theo pháp luật về quyền sở hữu công nghiệp; cũng chưa giải quyết được việc phân định quyền sở hữu đối với kết quả nghiên cứu trong trường hợp "sáng chế công vự" (Employee Invention)...

\section{Những rào cản trong trong quy định của pháp luật Việt Nam về truy cập mở và tài nguyên giáo dục mở}

\subsection{Rào cản quy định quyền sao chép thuờng xuyên và sao chép tạm thời}

Pháp luật Việt Nam về quyền tác giả quy định tại Khoản 10 Điều 4 Luật SHTT: Sao chép là việc tạo ra một hoặc nhiều bản sao của tác phẩm hoặc bản ghi âm, ghi hình bằng bất kỳ phương tiện hay hình thức nào, bao gồm cả việc tạo bản sao dưới hình thức điện tử.

Khoản 2 Điều 23 Nghị định 100/2006 NĐ$\mathrm{CP}$ : Quyền sao chép là quyền của chủ sở hữu quyền tác giả độc quyền thực hiện hoặc cho phép người khác thực hiện việc tạo ra bản sao của tác phẩm bằng bất kỳ phương tiện hay hình thức nào, bao gồm cả việc lưu trữ thường xuyên hoặc tạm thời tác phẩm dưới hình thức điện tử. Như vậy, pháp luật Việt Nam có quy định quyền sao chép tạm thời, nhưng lại không định 
nghĩa thế nào là tạm thời, có lẽ rất khó định nghĩa nên Nghị định 85/2011/NĐ-CP đã sửa lại bằng cách xóa "tạm thời”: Quyền sao chép tác phẩm là một trong các quyền tài sản độc quyền thuộc quyền tác giả, do chủ sở hữu thực hiện hoặc cho phép người khác thực hiện việc tạo ra bản sao tác phẩm bằng bất kỳ phương tiện hay hình thức nào, bao gồm cả việc tạo ra bản sao dưới hình thức điện tử.

Như vậy, có thể hiểu pháp luật Việt Nam về quyền tác giả không quy định về bản sao tạm thời tác phẩm dưới hình thức điện tử, đây là điểm khó khăn trong hoạt động quản lý quyền tác giả trong môi trường kỹ thuật số, trong đó có sự tồn tại của OER.

6.2. Rào cản quy định quyền của thu viện về sao chép và phân phối bản sao

Rào cản lớn nhất đối với thư viện trong việc quản lý OER là Điều 25 Nghị định 100/2006 (sửa đổi 2011) quy định Thư viện không được sao chép và phân phối bản sao tác phẩm tới công chúng, kể cả bản sao kỹ thuật số.

Theo khảo sát, tại Việt Nam đã có website thư viện pháp luật, nội dung đăng tải các của website này là hợp pháp theo quy định tại Khoản 2, Điều 15 Luật SHTT: Các đối tương không thuộc phạm vi bảo hộ quyền tác giả, văn bản quy phạm pháp luật, văn bản hành chính, văn bản khác thuộc lĩnh vực tu pháp và bản dịch chính thức của văn bản đó. Tuy nhiên, mục Thuật ngũ pháp lý của website Thư viện pháp luật vào thời điểm hiện tại vẫn bỏ trống, mà không hề có bất kỳ một thông tin nào, có lẽ Thư viện pháp luật phải chấp hành quy định đã nêu tại Điều 25 Nghị định 100/2006 (sửa đổi 2011).

Khảo sát một số thư viện thuộc các đại học cho thấy có:

- Mục Thu viện số, truy cập mở thuộc Thư viện Đại học Quốc gia Hà Nội;

- Mục Truy cập cơ sở dũ liệu thuộc Thư viện Đại học Quốc gia thành phố Hồ Chí Minh;

- Thư viện Đại học Bách khoa Hà Nội quy định: "Thư viện phục vụ tất cả nhu cầu in, sao tài liệu cho bạn đọc tại các bộ phận phục vụ. Bạn đọc có nhu cầu sao chép tài liệu, xin liên hệ với quầy thủ thư tại các phòng đọc".

Như vậy, thực tế cho thấy có nhu cầu về truy cập mở và tài nguyên giáo dục mở, do đó rất cần nghiên cứu để chỉnh sửa quy định tại Điều 25 Nghị định 100/2006 (sửa đồi 2011).

\section{Vận dụng quy định của pháp luật quốc tế về truy cập mở và tài nguyên giáo dục mở để khắc phục những rào cản đã nêu}

Để điều chỉnh quyền tác giả trong môi trường kỹ thuật số, năm 1996 WIPO đã ban hành Hiệp uớc của WIPO về quyền tác giả (The WIPO Copyright Treaty - WCT) ${ }^{12}$, trong đó đáng lưu ý quy định về bản sao tác phẩm dưới dạng số tại chú thích của Điều 1: ...như quy định ở Điều 9 của Công vớc Berne và các ngoại lệ đuợc cho phép theo đó, quyền sao chép hoàn toàn áp dung trong môi truờng ky thuât số, đặc biệt đối với việc sư dung các tác phẩm ở dạng kỹ thuật số. Điểm này được hiểu là việc lưu giũ một tác phẩm được bảo hộ duới dạng kỹ thuật số trong môi trường điện tử tạo thành việc sao chép theo nghĩa cúa Điều 9 Công uớc Berne. Như vậy, bản sao tác phẩm ngoài việc thể hiện ở dạng hữu hình thì còn được hiểu là thể hiện ở dạng vô hình (bản sao dưới dạng số).

Năm 1998, Hoa Kỳ ban hành Đạo luật về quyền tác giả kỹ thuật số thiên niên kỷ (The Digital Milenium Copyright Act), mặc dù Đạo luật này được ban hành nhằm thực hiện $\mathrm{WCT}$, nhưng trong Đạo luật này, Hoa Kỳ không quy định về bản sao dưới hình thức điện tử, mà dành quyền đó cho các cơ quan tư pháp khi xét xử.

Liên minh Châu Âu ban hành Chỉ thị số 2001/29/EC về Chỉ thị về sự điều hòa phối hợp một số khía cạnh của quyền tác giả và các quyền liên quan trong môi trường thông tin (Directive 2001/29/EC of the European Parliament and of the Council of 22 May 2001 on the harmonisation of certain aspects of

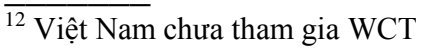


copyright and related rights in the infornation society). Tại Điều 5 Chỉ thị số 2001/29/EC quy định về ngoại lệ và giới hạn cách hiểu về hành vi làm bản sao tạm thời, là hành vi quá độ hoặc diễn ra ngẫu nhiên là một phần cấu tạo và phần quan trọng trong quy trình công nghệ với mục tiêu duy nhất là cho phép: (a) truyền dẫn trên mạng giữa các bên thứ ba do một bên trung gian thực hiện và (b) sử dụng hợp pháp đối với tác phẩm mà việc sử dụng đó không có ý nghĩa độc lập về kinh tế. ${ }^{13}$

Như vậy, sao chép thường xuyên và sao chép tạm thời đã được WCT và WPPT bàn đến. Vấn đề này đã được trao đổi rất nhiều, nhất là việc thực thi quyền sao chép tạm thời trong môi trường kỹ thuật số sẽ nảy sinh những bất cập trong quản lý.

WIPO (2005) cũng đã lưu ý những bất cập có thể xảy ra trong quy định về quyền sao chép thường xuyên hoặc tạm thời [15]. ${ }^{14}$ Band Jonathan and Jeny Marcinko (2005) và McJohn Stephen M. (2015) $[16,17]^{15}$ đã chỉ ra những bất cập trong việc thực thi quyền sao chép tạm thời, trong nhiều trường hợp là không thể xác định thế nào là những bản sao tạm thời (temporary copies), vì khi sử dụng máy tính bất kỳ một người nào cũng có thể xâm phạm quyền

\footnotetext{
13 Directive 2001/29/EC - Article 5. Exceptions and limitations: Temporary acts of reproduction referred to in Article 2, which are transient or incidental [and] an integral and essential part of a technological process and whose sole purpose is to enable: (a) a transmission in a network between third parties by an intermediary, or $(b) a$ lawful use of a work or other subject-matter to be made, and which have no independent economic significance...

${ }^{14}$ Xin tham khảo thêm mục III.29 trong tài liệu của WIPO (2005). Copyright in the Digital Environment: The WIPO Copyright Treaty (WCT) and the WIPO Performances and Phonograms Treaty (WPPT). Khartoum, February 28 to March 2, 2005

${ }^{15}$ Xin tham khảo thêm: Band Jonathan and Jeny Marcinko (2005). A New Perspective on Temporary Copies: The Fourth Circuit's Opinion in Costar v. Loopnet. Stanford Technology Law Review P1. McJohn Stephen M. (2015). Intellectual Property: Examples \& Explanations Series. Wolters Kluwer Law \& Business, 2015. IBSN 1454850159,9781454850151
}

sao chép tạm thời [18] ${ }^{16}$ (độc quyền của chủ sở hữu tác phẩm).

Câu hỏi mấu chốt được đặt ra: Trường hợp nào thì thư viện được phép sao chép để lưu trữ và phân phối tác phẩm đến công chúng?

Tại kỳ họp thứ 26 của Ủy ban Thường trực về quyền tác giả và quyền liên quan của $\mathrm{WIPO}^{17}$ đã thảo luận về quyền của thư viện trong việc bảo quản và lưu giữ tài liệu, trong đó quy định [19]:

a. Được phép sao chép các tác phẩm đã được xuất bản và chưa được xuất bản một cách hạn chế, bất kể định dạng của chúng, sao cho phù hợp với nhu cầu của thư viện và tài liệu lưu trữ mà không có sự cho phép của chủ sở hữu quyền tác giả;

b. Các bản sao tác phẩm được nêu tại khoản (a) chỉ được sử dụng để đáp ứng nhu cầu giảng dạy, nghiên cứu và bảo tồn di sản văn hóa (preservation of cultural heritage);

c. Các bản sao tác phẩm được nêu tại khoản (a) chỉ được sử dụng cho mục đích phi lợi nhuận, vì lợi ích chung của cộng đồng và cho sự phát triển của con người mà không mâu thuẫn với việc khai thác bình thường quyền tài sản đối với tác phẩm hoặc gây tổn hại bất hợp lý đến lợi ích hợp pháp của tác giả.

Cuộc thảo luận vào tháng 12.2013 tại Ủy ban Thường trực về quyền tác giả và quyền liên quan của WIPO đã phần nào loại bỏ các rào cản pháp lý để OER tồn tại, tuy nhiên đây mới chỉ là ý kiến thảo luận, cho đế thời điểm hiện tại, WIPO vẫn chưa "pháp điển hóa" ý kiến thảo luận này.

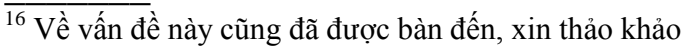
thêm: Đỗ Khắc Chiến (2009), 10 ẩn họa đối với lợi ich của Việt Nam. Người đại biểu Nhân dân số 221 (613) ngày $15 / 11 / 2009$

${ }^{17}$ WIPO, Standing Committee on Copyright and Related Rights (2013), Working document containing comments on a textual suggestions towards an appropriate international legal instrument (in whatever form) on exceptions and limitations for libraries and archives, Twenty-sixth Session, Geneva, December 16 to 20, 2013
} 


\section{Kết luận}

Bài viết đã phân tích sự cần thiết của truy cập mở và tài nguyên giáo dục mở đối với sự phát triển của $\mathrm{KH} \& \mathrm{CN}$, của giáo dục, đồng thời cũng phân tích những rào cản trong quy định của pháp luật Việt Nam về bảo hộ quyền tác giả đối với kết quả nghiên cứu khoa học khi cho phép truy cập mở và phát hành tài nguyên giáo dục mở. Những kinh nghiệm quốc tế và một số quốc gia mà bài viết đã nêu có thể là tài liệu cho các nhà hoạch định chính sách tham khảo để có thể nhanh chóng đưa kết quả nghiên cứu khoa học đến các nhà nghiên cứu và làm tài liệu giảng dạy trong trường học, với mục tiêu vì sự phát triển của khoa học và giáo dục.

Do tính phức tạp về pháp lý của việc bảo hộ quyền tác giả như nội dung bài viết đã nêu, đồng thời do hạn chế về khuôn khổ của một bài báo, bởi vậy bài viết này chưa thể bàn đến giải pháp chi tiết về chính sách quản lý truy cập mở và tài nguyên giáo dục mở đối với Việt Nam.

\section{Tài liệu tham khảo}

[1] Nathan Sivin (1995), Science in Ancient China: Researches and Reflections. Brookfield, Vermont: VARIORUM, Ashgate Publishing, Chapter III, pp. 16-19.

[2] Burke, James (1978). Connections. London: Macmillan Publishers. p. 101. ISBN 0-33324827-9

[3] Khong Dennis W. K. (2006). The Historical Law and Economics of the First Copyright Act. Erasmus Law and Economics Review 2, No. 1 (March 2006): 35-69

[4] WIPO (2009). Understanding Copyright and Related Rights. Publication No. 909(E) ISBN 978-92-805-1265-6

[5] Cao Minh Kiểm, Đinh Thị Thúy Quỳnh, Nguyễn Thị Thưa, Lưu Xuân Xa (2017), Chính sách thiết lập và truy cập mở tài nguyên số ở một số cường quốc trên thế giới, Tạp chí Chính sách và Quản lý KH\&CN, Tập 6, số $1 / 2017$, trang 52-65

[6] Noble, Ivan (2002). Boost for research paper access. BBC News. London, Retrieved 12 February 2012.
[7] OECD - Centre for Educational Research and Innovation (2007), Giving Knowledge for Free. The Emergence of Open Educational Resources

[8] Charles C. Fries (1981), American English Grammar, Irvington Pub, ISBN-13: 9780891970101 ISBN-10: 089197010X

[9] OECD (2004), Principles and Guidelines for Access to Research Data from Public Funding

[10] G8 (2013), Open Data Charter, June 2013

[11] Eliot A. Phillipson and Co-authors (2012), The State of Science and Technology in Canada, 2012, (C) 2012 Council of Canadian Academies Printed in Ottawa, Canada, 2012, p 164 - 180

[12] USPTO (2014), Patents by Country, State, and Year - All Patent Types, Granted: 01/01/1977 12/31/2014. A Patent Technology Monitoring Team Report

[13] Vũ Cao Đàm (2010), Giáo trình Phương pháp luận nghiên cứu khoa học, Nhà xuất bản Giáo dục, Hà Nội, 2010

[14] Trần Văn Hải (2009), Xác định chủ sở hữu của kết quả nghiên cứu khoa học, Tạp chí Hoạt động khoa học, số 598 tháng 3.2009, trang 3336. ISSN 1859-4794

[15] WIPO (2005). Copyright in the Digital Environment: The WIPO Copyright Treaty (WCT) and the WIPO Performances and Phonograms Treaty (WPPT). Khartoum, February 28 to March 2, 2005

[16] Band Jonathan and Jeny Marcinko (2005). A New Perspective on Temporary Copies: The Fourth Circuit's Opinion in Costar v. Loopnet. Stanford Technology Law Review P1.

[17] McJohn Stephen M. (2015). Intellectual Property: Examples \& Explanations Series. Wolters Kluwer Law \& Business, 2015. IBSN 1454850159, 9781454850151

[18] Đỗ Khắc Chiến (2009), 10 ẩn họa đối với lợi ích của Việt Nam. Người đại biểu Nhân dân số 221 (613) ngày 15/11/2009

[19] WIPO, Standing Committee on Copyright and Related Rights (2013), Working document containing comments on a textual suggestions towards an appropriate international legal instrument (in whatever form) on exceptions and limitations for libraries and archives, Twenty-sixth Session, Geneva, December 16 to 20, 2013. 


\title{
Barriers in Copyright Protection Policy for Open Access and Open Educational Resources
}

\author{
Tran Van Hai \\ VNU University of Social Sciences and Humanities, 336 Nguyen Trai, Thanh Xuan, Hanoi, Vietnam
}

\begin{abstract}
The generation of Internet has had a great impact on copyright in general. It is the internet to help authors conveniently and quickly bring their work to the public conveniently and quickly. But it is also the internet to let unauthorized copying issue to happen, damaging the property rights of the work's owner.

In scientific research, there is a need for rapid sharing research results, since it supports the development of science and technology, thus forming a need for "open access". Similarly, in education and training, the urgent task of rapidly transfer science and technology knowledge developed elsewhere to school forms a need for "open educational resources". Open access and open educational resource are inseparable from the internet as the access tools. However, they are causing conflicts in the protection of copyright and the development of the internet.
\end{abstract}

This paper aims to analyze the barriers in copyright protection for open access and open educational resources.

Keywords: Copyright, Open Access, Open Educational Resources. 